\title{
Eastern Tropical Atlantic Mixed Layer Depth: Assessment of Methods from In Situ Profiles in the Gulf of Guinea from Coastal to High Sea
}

\author{
N'Guessan Benjamin Kouadio 1, 2, *, Kouassi Aka Marcel ${ }^{1}$, Trokourey Albert ${ }^{2}$, Toualy Elisée ${ }^{3}$, \\ Kanga Desiré Kouamé ${ }^{1,2}$, Brehmer Patrice ${ }^{4}$
}

${ }^{1}$ Centre de Recherches Océanologiques (CRO), Abidjan, Côte d'Ivoire

2 UFR SSMT, Université Felix Houphouët-Boigny, Laboratoire de Chimie-Physique, Abidjan, Côte d'Ivoire

3 UFR SSMT, Université Felix Houphouët-Boigny, Laboratoire de Physique de l'Atmosphère et de Mécanique des Fluides (LAPA-MF), Abidjan, Côte d'Ivoire

${ }^{4}$ IRD, Univ Brest, CNRS, Ifremer, Lemar, Délégation Régionale IRD Oues, tPlouzané, France

${ }^{*}$ Corresponding author : Benjamin Kouadio N'Guessan, email address :

nguessan.k.benjamin@gmail.com

\begin{abstract}
:
To assess the eastern Atlantic tropical mixed layer depth (MLD) at $4^{\circ} \mathrm{W}$ in the Gulf of Guinea, water temperature and density profiles from over five hundred historical observational Conductivity Temperature - Depth (CTD) data were used. These data, obtained from key oceanographic survey databases covering 60 years (1956 to 2016) were used for a numerical and visual determination of the MLD. The numerical approach consists of the use of the algorithms of three methods; while the visual estimation of the MLD were made on both temperature and density profiles. The numerical approaches were evaluated by comparing their results on the determination of tropical MLD with those of the visual inspections by means of statistical and graphical analysis in order to determine the most suitable method for the determination of MLD in the study area. Our results show that the Boyer Montegut density threshold method (potential density) with the constant criterion $\Delta \sigma=0.03 \mathrm{~kg} \cdot \mathrm{m}-3$ and a reference depth of ten meters is the most appropriate for determining the MLD in the Gulf of Guinea regardless the season. However, in the situation where only temperature profiles are available it is advisable to estimate MLD using the Lorbacher curvative method.
\end{abstract}

Keywords : Mixed layer depth, Gulf of Guinea, Atlantic Ocean, Density, Temperature 


\section{INTRODUCTION}

The mixed layer depth (MLD) of the ocean is commonly considered as the area near the surface with vertically quasi-uniform ocean tracers (temperature, salinity, density) above a layer of more rapid vertical changes (Lorbacher et al., 2006). It is the manifestation of vigorous turbulent mixing processes which are active in the upper layers of the ocean. The transfer of mass, momentum and energy across the mixed layer provides the source of almost all ocean motions and the thickness of the mixed layer determines the heat content of the mechanical inertia of the layer that directly interact with the atmosphere (de Boyer Montégut et al., 2004). The MLD is generally estimated from temperature and density profiles using several approaches. The first two methods are the threshold and gradient approaches (Sprintall and Tomczak 1992; Sprintall and Roemmich 1999; Kara et al., 2000; Thomson and Fine, 2010). The threshold and gradient methods fix the shallowest depth where chosen threshold or gradient criterion is achieved. The third method was developed by Lorbacher et al. (2006) who estimated MLD using the curvative of the profile. This approach searches for the first extreme curvative of the profile, analyses the profile at nearly levels and defines MLD. The fourth method was that of Holte and Talley (2009) which is a hybrid method for finding the mixed layer depth (MLD) of individual ocean profiles (temperature, salinity, and density). This approach selects the final MLD from possible MLD values estimated from the threshold and gradient methods but also by looking for some physical characteristics of the profile such as thermocline / pycnocline, location of maxima or minima of the profile, intrusions to the base of the mixed layer.

The Gulf of Guinea is a dynamic and complex ecosystem along the equatorial West African coasts, approximately extending from Guinea-Bissau to Gabon (Tilot and King 1993, Binet and Marchal 1993; Nieto et al., 2017). This region benefits from a high level of incoming solar radiation and hot waters that promotes plankton which in turn supply food for fishes and sustain fisheries, a key source of revenue for economic and social development for the countries of the region (Nieto et $\boldsymbol{a l . , ~ 2 0 1 7 ) . ~ T h e ~ G u l f ~ o f ~ G u i n e a ~ i s ~ a ~ v e r y ~ i m p o r t a n t ~ a r e a ~ f o r ~ f i s h e r i e s ~}$ showing a high degree of both physical and biological environmental variability (HardmanMountford, 2000) whose study is facing lack of observational data of good quality and spatiotemporal resolution. 
Studies in relation with mixed layer in the Gulf of Guinea were undertaken by Peter et $\boldsymbol{a l}$. (2006) and Wade (2010) respectively on salt and heat balance of the mixed layer from a set of satellite and observation data. The threshold method was used by these two studies.

The objective of this study is to explore several approaches commonly used to calculate the MLD and to determine the most suitable for its determination in the Gulf of Guinea.

\section{METHODS}

\subsection{Data, processing and control}

The data used in this study were extracted from a box centered on $4^{\circ} \mathrm{W} \pm 0.25^{\circ}$ and limited by latitudes $\mathbf{5}^{\circ} \mathbf{N}-\mathbf{1 0}{ }^{\circ} \mathbf{S}$ (Fig. 1).

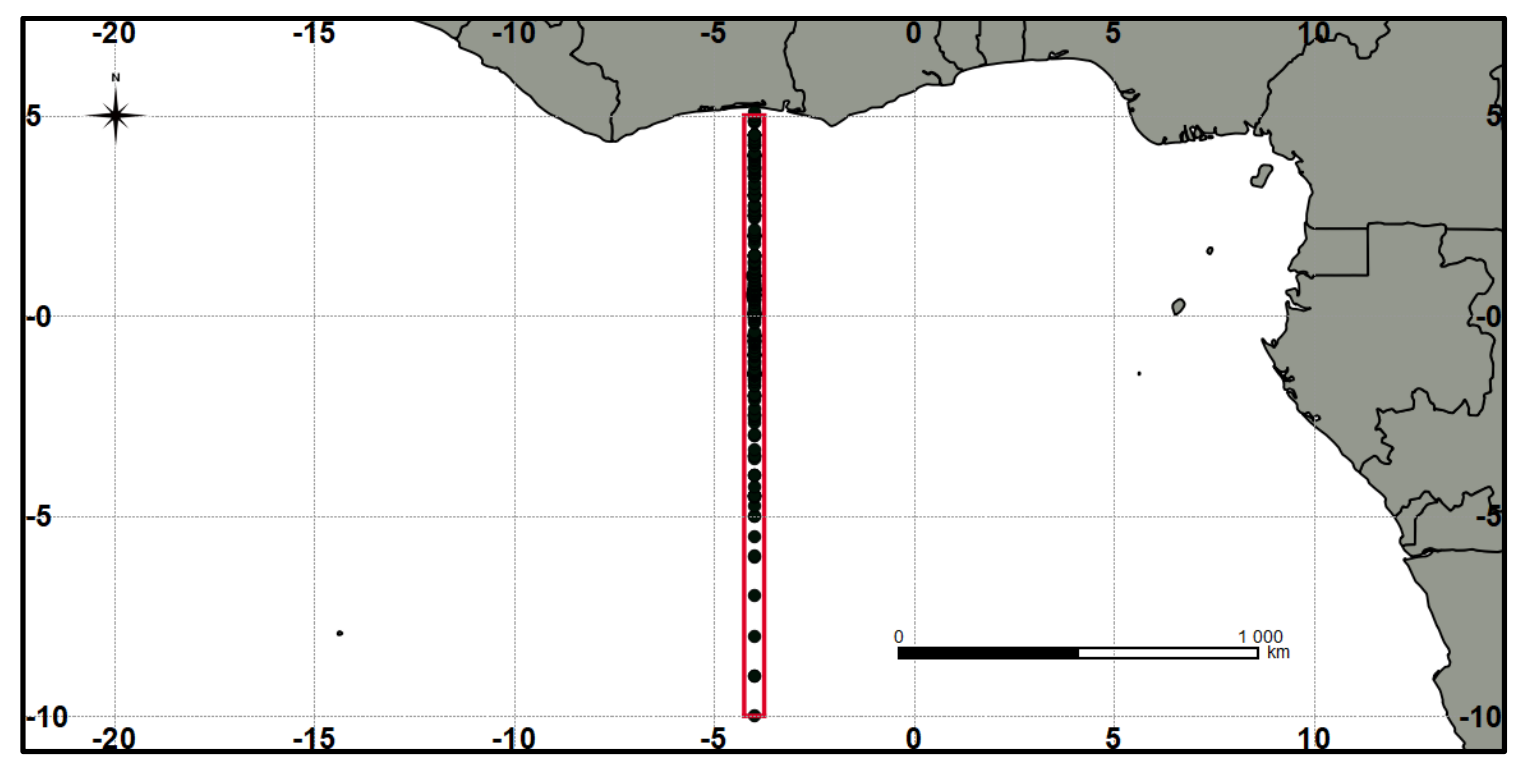

Fig. 1 Study area showing the red box $\left(5^{\circ} \mathrm{N}, 4.25^{\circ} \mathrm{W} ; 5^{\circ} \mathrm{N}, 3.75 \mathrm{~W} ; 10^{\circ} \mathrm{S}, 4.25^{\circ} \mathrm{W} ; 10^{\circ} \mathrm{N}, 3.75 \mathrm{~W}\right)$ where data were extracted at $4^{\circ} \mathrm{W}$ in the Gulf of Guinea

These are historical observational CTD (Conductivity-Temperature-Density) data of irregular spatial and temporal resolution from three oceanographic survey databases: The Systèmes d'Informations Scientifiques pour la Mer (SISMER) data (https://data.ifremer.fr/SISMER) from 1956 to 2016, the World Ocean Database 2013 (WOD13) data (Boyer et al., 2013) extracted between 1971 and 2016 and the CORIOLIS data (http://www.coriolis.eu.org) covering the period 1956 to 2016 . The number of some stations from SISMER were reassigned to avoid duplicates.

Stations without temperature, salinity or pressures (depths) data were not considered. The data files were then restructured by year and by campaign. The potential densities were calculated 
and the depths (in meters) of the WOD13 data profiles were converted to pressures (dbar) using the CSIRO SeaWater Library (version 3.3.1) in Matlab software (Matrix Laboratory).

The temperature, salinity and density profiles from the raw data of the stations were plotted. Visual inspection and correction of these profiles were also performed according to Maheswaran (2004) and Nahavandian (2014). Profiles containing no more than three depth levels points were not considered because the algorithm computes moving averages of order 3 . Profiles with low vertical resolutions $(>10 \mathrm{~m})$ in the first 50 meters were removed. Finally, profiles with a maximum depth of less than or equal to $50 \mathrm{~m}$ were also deleted because, according to the Climatology of de Boyer Montégut et al. (2004), the study area has a MLD maximum around $60 \mathrm{~m}$. For CTD profiles with one or more missing values in the first 100 meters, the values were replaced by the bottle data from the same station and same campaign if they are available. When no replacement value existed for intermediate levels between two measured values, they were replaced by the average of the two values that surround it.

From these data treatments, 1209 stations were obtained: 417 for WOD13, 122 for CORIOLIS and 670 for SISMER databases. The Individual temperature, salinity, and density profiles of these stations were used for numerical determination of MLD using the algorithms of Holte and Talley (2009), Thomson and Fine (2003) and Lorbacher et al. (2006). Data that did not satisfy the inclusion conditions of the algorithms were removed. Finally, a total of 516 stations spanning 46 years between 1971 and 2016 are obtained and displayed in Table 1. 
Table 1: Number of stations $(\mathrm{N}=516)$ per year and month between 1971 and 2016 used for the study.

\begin{tabular}{|c|c|c|c|c|c|c|c|c|c|c|c|c|c|}
\hline \multirow{2}{*}{ Years } & \multicolumn{7}{|c|}{ Hot season } & \multicolumn{3}{|c|}{ Cold season } & Total \\
\hline & Nov. & Dec. & Jan. & Feb. & Mar. & Apr. & May. & Jun. & Jul. & Aug. & Sep. & Oct. & \\
\hline 1971 & 4 & - & - & - & - & - & - & - & - & - & - & - & $\mathbf{4}$ \\
\hline 1972 & - & - & - & - & - & - & 1 & - & - & - & 18 & - & $\mathbf{1 9}$ \\
\hline 1973 & 11 & - & - & - & - & - & - & - & - & - & - & - & $\mathbf{1 1}$ \\
\hline 1974 & - & - & - & - & - & - & - & - & 13 & - & - & - & $\mathbf{1 3}$ \\
\hline 1975 & - & - & 3 & - & - & - & - & - & - & - & - & - & $\mathbf{3}$ \\
\hline 1977 & - & - & 22 & 7 & - & - & - & - & 6 & - & - & - & $\mathbf{3 5}$ \\
\hline 1978 & - & - & - & - & - & - & - & - & - & 129 & 24 & - & $\mathbf{1 5 3}$ \\
\hline 1979 & - & - & 19 & - & - & - & - & 7 & - & - & - & - & $\mathbf{2 6}$ \\
\hline 1980 & - & - & 1 & - & - & - & - & - & - & - & - & - & $\mathbf{1}$ \\
\hline 1982 & 11 & - & - & - & - & - & - & - & 12 & - & - & - & $\mathbf{2 3}$ \\
\hline 1983 & - & - & - & 8 & - & 13 & - & - & - & 11 & - & 1 & $\mathbf{4 1}$ \\
\hline 1984 & - & - & - & 12 & - & - & 25 & 14 & 22 & - & - & - & $\mathbf{7 3}$ \\
\hline 1985 & - & - & - & - & - & - & - & - & 7 & - & - & - & $\mathbf{7}$ \\
\hline 1988 & - & - & - & - & 15 & - & - & - & - & - & - & - & $\mathbf{1 5}$ \\
\hline 1993 & - & - & 1 & - & 23 & - & - & - & - & - & - & - & $\mathbf{2 4}$ \\
\hline 2004 & - & - & - & - & 1 & - & - & - & - & - & - & - & $\mathbf{1}$ \\
\hline 2005 & - & - & - & - & - & - & - & - & - & - & - & 1 & $\mathbf{1}$ \\
\hline 2006 & - & - & - & - & - & 1 & 1 & - & - & - & - & - & $\mathbf{2}$ \\
\hline 2007 & 1 & 1 & - & - & - & - & - & - & - & - & - & - & $\mathbf{2}$ \\
\hline 2008 & - & - & - & 2 & 1 & - & - & - & - & 2 & - & - & $\mathbf{5}$ \\
\hline 2009 & - & - & - & - & - & - & - & - & 1 & - & - & 1 & $\mathbf{2}$ \\
\hline 2010 & - & - & - & - & - & - & - & - & 1 & - & - & - & $\mathbf{1}$ \\
\hline 2011 & - & - & 1 & - & - & - & - & - & 1 & - & 2 & - & $\mathbf{4}$ \\
\hline 2012 & - & - & - & - & - & 1 & - & 1 & - & 1 & - & 1 & $\mathbf{4}$ \\
\hline 2013 & - & - & 1 & - & - & 1 & - & - & - & - & - & - & $\mathbf{2}$ \\
\hline 2014 & - & 1 & - & - & - & - & 20 & 2 & - & 1 & - & - & $\mathbf{2 4}$ \\
\hline 2015 & 1 & - & 2 & - & 1 & - & - & - & - & - & 2 & 1 & $\mathbf{7}$ \\
\hline 2016 & - & 3 & - & 1 & - & - & 5 & 2 & - & 1 & 1 & - & $\mathbf{1 3}$ \\
\hline Total & $\mathbf{3 6}$ & $\mathbf{5}$ & $\mathbf{5 0}$ & $\mathbf{3 0}$ & $\mathbf{4 1}$ & $\mathbf{1 6}$ & $\mathbf{5 2}$ & $\mathbf{2 6}$ & $\mathbf{6 3}$ & $\mathbf{1 4 5}$ & $\mathbf{4 7}$ & $\mathbf{5}$ & $\mathbf{5 1 6}$ \\
\hline & & & & & & & & & & & \\
\hline
\end{tabular}

The temperature and density profiles were first vertically interpolated before the determination of the MLD. The numerical determination of MLD were based on the algorithms of three methods developed by Lorbacher et al., (2006), Thomson and Fine (2003) and Holte and Talley (2009). The Holte and Talley method uses the threshold and gradient approaches and special algorithms for either temperature or density to estimate MLD. The visual determinations were made by visual inspection of the MLD on the temperature and density profiles of the 516 stations graphically represented. The algorithms and their results were abbreviated respectively by LORB, TF and HT (Table 2). 
Table 2: Codification of mixed layer depth (MLD) obtained from different methods of determination, based on conductivity temperature and depth (CTD) profile. LORB: Lorbacher method; TF: Thomson and Fine method; HT: Holte and Talley method. Temp: MLD from temperature profile. Dens: MLD from density profile. Temp Thres: Temperature threshold criterium; Dens Thres: Density threshold criterium; Dens Grad: Density Gradient criterium; Algo: MLD from temperature or density algorithm. Visu: MLD from visual inspection. The alphabetic letters represent these different methods variants.

\section{Codification of results (MLD)}

\begin{tabular}{lll}
\hline \multicolumn{1}{c}{ Methods } & \multicolumn{1}{c}{ Temperature-based MLD } & \multicolumn{1}{c}{ Density-based MLD } \\
\hline \multirow{3}{*}{ Holte and Talley, 2009 (HT) } & A: HT Temp Algo & B: HT Dens Algo \\
& C: HT Temp Thres & D: HT Dens Thres \\
& E: HT Temp Grad & F: HT Dens Grad \\
\hline Lorbacher et $\boldsymbol{a l . , \text { 2006 (LORB) }}$ & G: LORB Temp & H: LORB Dens \\
\hline Thomson and Fine, 2003 (TF) & I: TF Temp & J: TF Dens \\
\hline Visual inspection & Visu Temp & Visu Dens \\
\hline
\end{tabular}

\subsection{Numerical methods evaluation}

The evaluation of the methods consisted of comparing the results (MLD) of the different variants of the three numerical methods with visually determined MLD (which serve as reference values) on the temperature and density profiles in both hot and cold seasons (You, 1995, Sprintall and Roemmich, 1999, Kara et al., 2000, Ohno et al., 2009). This is done through statistical and graphical analysis of method performance from Taylor diagrams (Taylor, 2001) and 2D diagrams of linear correlations between pairs of methods (Maheswaran, 2004; Nahavandian, 2014).

\subsubsection{Evaluation using the Taylor diagrams}

Two diagrams are drawn: One for temperature-based methods and another one for densitybased methods. Ten variants represented by alphabetical letters are evaluated: A, C, E, G and I for the five variables based on temperature; B, D, F, H and $\mathrm{J}$ for the five density based. The reference values are represented by Visu Temp and Visu Dens. Three different statistics are analyzed: mean, standard deviation (STD), Root-Mean-Square Deviation (RMSD) and the correlation coefficient of Bravais-Pearson ( $\mathrm{r}$ instead of $\mathrm{R}^{2}$ ). The lower the RMSD, the closer the variant is to the reference and is therefore able to reproduce the reference values (Taylor, 2001).

\subsubsection{Evaluation using the linear correlation diagrams}

Linear correlation diagrams were used to determine the adjustment line, the linear correlation coefficient $\left(\mathrm{R}^{2}\right)$ test the significance of the correlation and analyze the distribution of the scatter plot with respect to the first bisector, which gave information on the bias of methods. 
Table 3: MLD results statistics based on numerical methods. For abbreviations refer to Table 2.

The MLD estimated by the HT, TF and LORB numerical methods are between 0 and $72 \mathrm{~m}$. In

The significance of the correlations was tested through the values of the p-values (Alboukadel, 2018). These diagrams compare digital MLD and visual MLD. The evaluation target for the numerical variant whose linear correlation with the visual methods has the highest correlation coefficient $\mathrm{R}$ and whose results are the least biased possible.

Finally, the numerical variant chosen to determine the MLD is the one that has the following characteristics: The point representing the variant is the closest to that of the reference on the Taylor diagram; This variant has a high correlation coefficient with the reference; It gives the most comparable results possible with the reference, that is to say does not underestimate nor overestimate the MLD compared to the reference values on the 2D diagrams.

\section{RESULTS AND DISCUSSIONS}

\subsection{Analysis of MLD numerical determinations}

Five hundred and sixteen (516) MLD values including 260 for the cold season and 256 for the hot season are determined. Table 3 displays the minimum, maximum and average values of MLD.

both hot and cold seasons, the minimum values obtained from HT and TF methods are all around $10 \mathrm{~m}$ (reference depth). The maximum MLD is obtained from the temperature profiles with the TF method and the lowest MLD with LORB methods regardless the season.

The LORB method, unlike the threshold and gradient methods, does not critically depend on the choice of the reference depth. According to Lorbacher et al. (2009), the curvative method generally gives lower MLD than with the temperature threshold criterion of de Boyer Montégut et al. (2004). The results of their work showed that in about $70 \%$ of the highresolution CTD profiles that were the subject of their work, their method underestimated the 
values with respect to de Boyer Montégut temperature threshold criterion (de Boyer Montégut et $a l .$, 2004). The low observed values could also be explained by the interpolations (linear and/or exponential) between the different depths leading to underestimation of the MLD. Moreover, in the tropics, at about $\pm 20^{\circ}$ latitude of the equator, the water column is weakly stratified below the surface and the temperature profiles in the upper part of the main thermocline are concave, producing vertical gradients that sometimes result in lower MLD (Lorbacher et al., 2009). Finally, according to Tanguy et al. (2010), the Lorbacher method is based on gradient calculations and is very sensitive to small variations that may be caused by diurnal mixing or may be influenced by a weaker stratification at the bottom of the mixed layer.

Table 4 shows the proportions (\%) of MLD determined with the different possibilities in the HT method.

Table 4: Proportions (in \%) of mixed layer depth (MLD) determined with the different HT method possibilities.

\begin{tabular}{cccc}
$\begin{array}{c}\text { Threshold } \\
\text { criterion }\end{array}$ & $\begin{array}{c}\text { Gradient } \\
\text { criterion }\end{array}$ & $\begin{array}{c}\text { line (pycnocline) and the line fitted } \\
\text { to the profile « adjustment lines } \\
\text { criterion» }\end{array}$ & $\begin{array}{c}\text { Other } \\
\text { possibilities }\end{array}$ \\
\hline
\end{tabular}

\begin{tabular}{lcccc}
\hline Temperature profiles & 54 & 8 & 35 & 3 \\
\hline Density profiles & 37 & 11 & 49 & 3 \\
\hline
\end{tabular}

The HT method has six variants that use in addition to threshold and gradient criteria, the process of assigning the MLD by the algorithm itself. This process chooses among several possibilities of values of MLD, the value which is appropriate for the type of studied profile.

Table 4 shows that $35 \%$ of the MLD correspond to the « adjustment lines criterion »; $8 \%$ of the MLD are obtained from the gradients criterion and 3\% from the depth of the maximum temperature (here referred as other possibility). The threshold temperature criterion $\left(0.2^{\circ} \mathrm{C}\right)$ gives the majority proportion with 54\% of the MLD. In their study Holte and Talley (2009) obtained $58 \%$ of the MLD with the «adjustment lines criterion », $22 \%$ with the threshold criterion and $9 \%$ with the gradient criterion. The adjustment lines criterion using density profiles determines the largest proportion of MLD corresponding to $49 \%$, while $37 \%$ have been estimated with the density threshold, $11 \%$ with the gradient criterion and $3 \%$ with the other possibilities. These results show the importance of HT density algorithm in the determination of the MLD with the density profiles and indicates the strong dependence of the MLD on the structure of the density profile. 
185 In addition, the MLD values determined from the other possibilities (3\% on the temperature profiles and $3 \%$ on the density profiles) show that in the study area some salinity intrusions and temperature inversion occur and could lead to barrier layers. The results of this study are supported by de Boyer Montégut et al. (2004), who identified and confirmed the existence of barrier layers in the western equatorial Pacific Ocean during all seasons (between $15^{\circ}$ and $15^{\circ} \mathrm{N}$ and $150^{\circ} \mathrm{E}, 160^{\circ} \mathrm{W}$ ), in all regions of the ITCZ (Intertropical Convergence Zone) and the South Pacific Convergence Zone, in the Bay of Bengal and the Eastern Equatorial Indian Ocean and in the western tropical Atlantic Ocean. In the tropical Atlantic Ocean, these barrier layers originate from advective processes or from the continental runoff of the Amazon River, as also concluded by Sprintall and Tomczak (1992). The thick barrier layers of the western tropical Atlantic have also been detected in the deep tropical Atlantic basin, in the equatorial zone $\left(5^{\circ} \mathrm{S}\right.$ $-10^{\circ} \mathrm{N}$ ) and could be associated in part with significant vertical temperature inversions (Mignot et al., 2007).

The results obtained from the study also confirm the existence of barrier layers in the eastern part of the Atlantic basin at $4^{\circ} \mathrm{W}$ as in the western tropical Atlantic. Indeed, according to the results of the HT algorithm, temperature inversions as well as salinity intrusions could be observed on the temperature and density profiles listed in Table 5 and represent $3 \%$ of the profiles on which the MLD were determined by the other possibilities. 
Table 5: Temperature and density profiles indicating salinity intrusions and temperature inversions and their MLD. Months indicate the numbers of corresponding months between 1 to 12 . Stations 520 and 610 and their numbers are from SISMER. The other stations and their numbers are from WOD13. For abbreviations refer to Table 2

\begin{tabular}{|c|c|c|c|c|c|c|c|c|c|}
\hline \multicolumn{5}{|c|}{ Temperature profiles } & \multicolumn{5}{|c|}{ Density profiles } \\
\hline Stations & Latitudes & Months & Years & $\begin{array}{c}\text { MLD from } \\
\text { temperature } \\
\text { profiles } \\
\text { (HT Temp Algo) }\end{array}$ & Stations & Latitudes & Months & Years & $\begin{array}{c}\text { MLD from } \\
\text { density profiles } \\
\text { (HT Dens Algo) }\end{array}$ \\
\hline 3285750 & 4 & 5 & 1984 & 26 & 7744382 & 3 & 3 & 1993 & 29 \\
\hline 7744382 & 3 & 3 & 1993 & 29 & 3374546 & 2,7483 & 3 & 1988 & 30 \\
\hline 3374546 & 2,7 & 3 & 1988 & 30 & 3374546 & 2,7483 & 3 & 1988 & 30 \\
\hline 3374546 & 2,7 & 3 & 1988 & 30 & 3287311 & 2 & 7 & 1984 & 29 \\
\hline 3285744 & 2,5 & 5 & 1984 & 34 & 610 & 1,483 & 9 & 1978 & 30 \\
\hline 3287311 & 2 & 7 & 1984 & 29 & 16025395 & 1,477 & 6 & 2014 & 36 \\
\hline 610 & 1,5 & 9 & 1978 & 30 & 3321928 & 1,283 & 9 & 1972 & 32 \\
\hline 16025395 & 1,5 & 6 & 2014 & 36 & 3332145 & 1 & 1 & 1977 & 26 \\
\hline 3321928 & 1,3 & 9 & 1972 & 32 & 3322092 & 0,75 & 9 & 1972 & 30 \\
\hline 3322092 & 0,8 & 9 & 1972 & 30 & 3336428 & 0,062 & 8 & 1978 & 26 \\
\hline 520 & 0,6 & 8 & 1978 & 30 & 3336433 & 0,02 & 8 & 1978 & 32 \\
\hline 3336428 & 0,1 & 8 & 1978 & 26 & & & & & \\
\hline 3336433 & 0 & 8 & 1978 & 32 & & & & & \\
\hline
\end{tabular}

\subsection{Analysis of visual determinations of MLD}

205 Visual inspections of profiles have been achieved for both coastal and equatorial zones for the

206 hot and cold season. These profiles have shown different hydrographic structures that can be classified into three main types: The classical, the progressive and the graduated types as suggested by Taï et $\boldsymbol{a l}$. (2017). Examples of the three types of profiles encountered are shown in Fig. 2. 


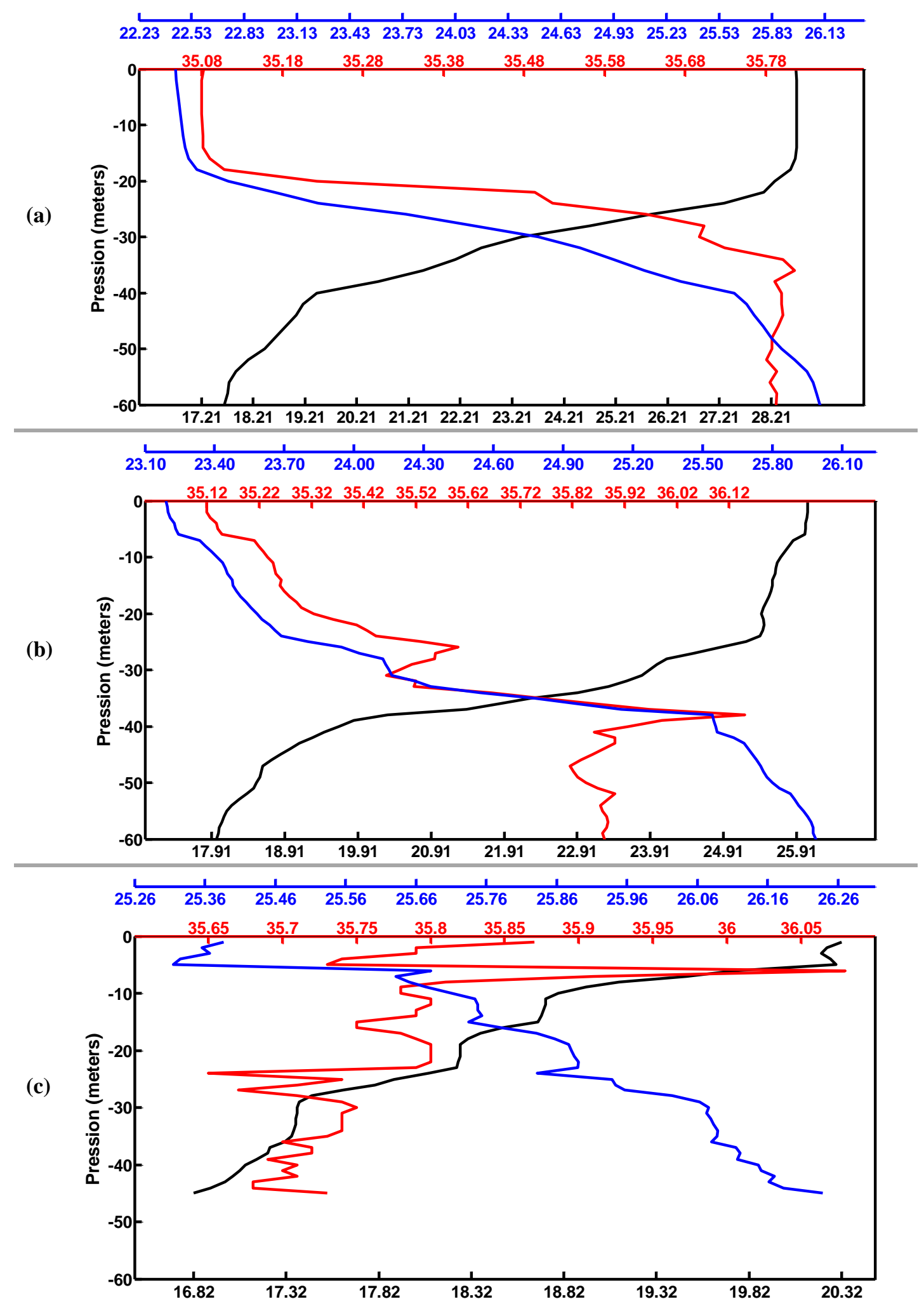

Fig. 2 Examples of different profiles types observed at $4^{\circ} \mathrm{W}$. Black line: Temperature. Red line: Salinity. Blue line: Density. (a): Classical type: MLD clearly identified by sudden changes in depth gradients. Example: station 3374548; Year: 1988; Month: August; Latitude: $4.2467^{\circ}$ N. (b): Progressive type: MLD is not easily defined. Example: Example: station: 3352851; Year: 1983; Month: October; Latitude: $4.8283^{\circ}$ N. (c): Graduated type: MLD not identified visually (profiles not considered). Example: station: 7728798; Year: 1998; Month: August; Latitude: $5.0107^{\circ} \mathrm{N}$ 
218 The classical type structures show profiles with a surface layer without pronounced gradients,

219 covering the main thermocline (or the pycnocline). The mixed layer is clearly differentiated by 220 a sudden change in depth gradients. This classic type is the one that Holte and Talley (2009) 221 call "summer profile".

222 Progressive type structures have slight temperature (or density) gradients in the mixed layer. 223 The abrupt change in depth gradient that marks the boundary of the mixed layer is not clearly 224 identifiable, so the MLD is not easily defined. This second type seems to be the one Holte and 225 Talley (2009) call "winter profile".

226 Graduated type structures have successive pronounced gradients that do not allow easy 227 identification and measurement of the MLD. Hence, the latter structures were not considered 228 for the rest of the study. Of the two remaining profile types, the results indicate that $69 \%$ of 229 MLD were determined on "summer profiles" and $31 \%$ on "winter profile".

230 Our results differ from those of Taï et al. (2017) who obtain about $85 \%$ of classical and 231 progressive type profiles in their study of the structure of surface water and the thickness of the 232 mixed layer in the tropical waters of the North China Sea over the period 1997-2013.

\subsection{Evaluation of methods using Taylor diagrams}

The Taylor diagrams between the numerical variants and their respective references to temperature and density profiles in hot and cold seasons are shown in Fig. 3. Table 6 presents the statistical parameters derived from these Taylor diagrams. 


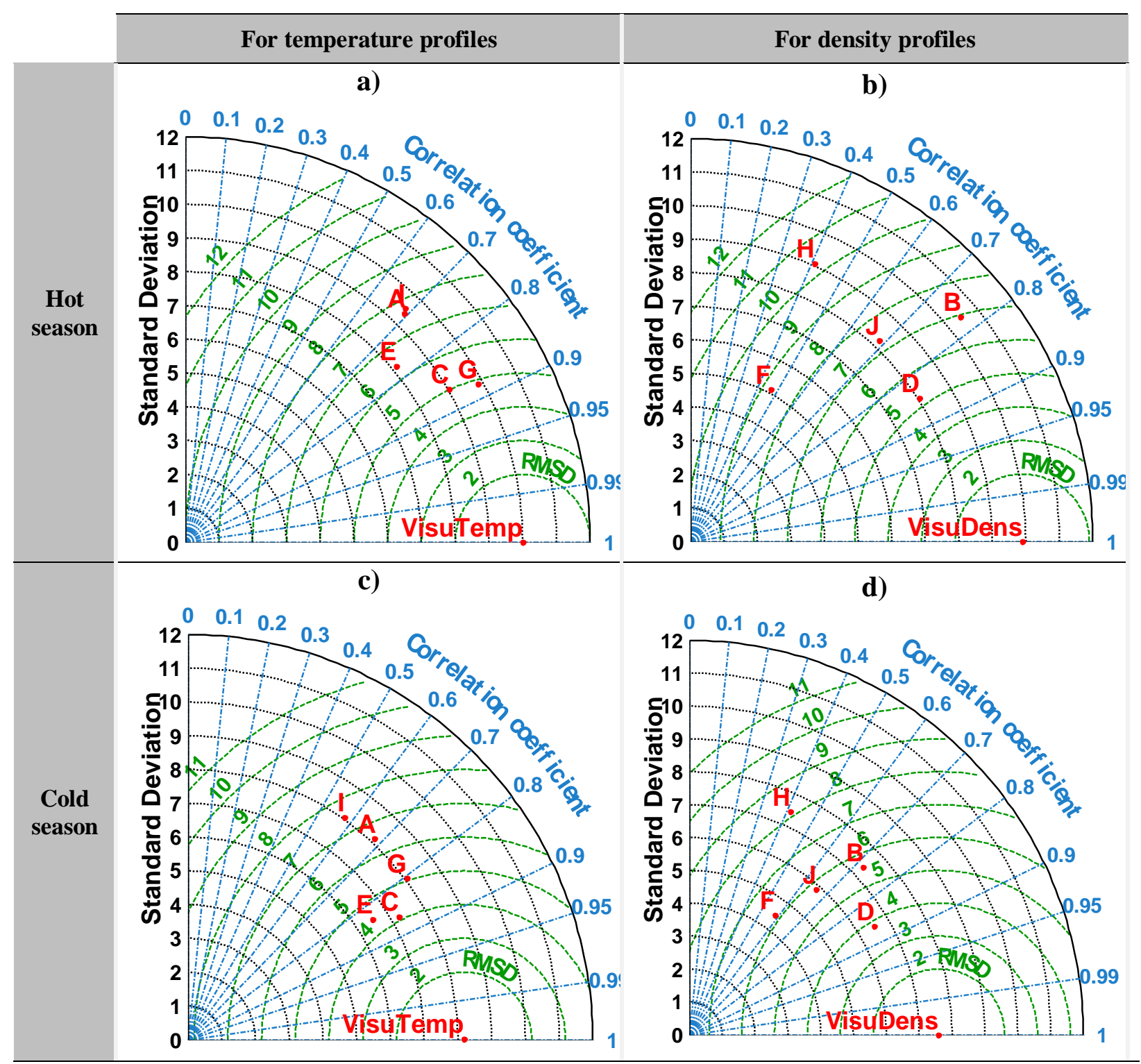

Fig. 3 Taylor diagrams: Comparison between numerical methods and visual determinations during hot (a, b) and cold (c, d) season. A: HT Temp Algo, B: HT Dens Algo, C: HT Temp Thres, D: HT Dens Thres, E: HT Temp Grad, F: HT Dens Grad, G: LORB Temp, H: LORB Dens, I: TF Temp, J: TF Dens. RMSD: Root-Mean Square Deviation 
Table 6: Statistical parameters from Taylor diagram based on the reference Visu Dens. The MLD estimates from variants $\mathrm{B}, \mathrm{D}, \mathrm{F}, \mathrm{H}$ and $\mathrm{J}$ are compared to those from visual determination on density profiles. RMSD: RootMean-Square Deviation. $r$ and $\mathrm{R}^{2}$ : Bravais-Pearson correlation coefficient. For abbreviations refer to Table 2.

\begin{tabular}{|c|c|c|c|c|c|c|c|}
\hline & $\begin{array}{c}\text { Statistical } \\
\text { parameters }\end{array}$ & $\begin{array}{c}\text { Reference } \\
\text { (Visu } \\
\text { Dens) }\end{array}$ & $\begin{array}{c}\text { HT } \\
\text { Dens } \\
\text { Algo } \\
\text { (B) }\end{array}$ & $\begin{array}{l}\text { HT Dens } \\
\text { Thres } \\
\text { (D) }\end{array}$ & $\begin{array}{l}\text { HT Dens } \\
\text { Grad } \\
(\mathrm{F})\end{array}$ & $\begin{array}{l}\text { LORB } \\
\text { Dens } \\
(\mathrm{H})\end{array}$ & $\begin{array}{c}\text { TF Dens } \\
(\mathrm{J})\end{array}$ \\
\hline \multirow{4}{*}{$\begin{array}{c}\text { Hot } \\
\text { season }\end{array}$} & Means & 18,64 & 22,47 & 19,16 & 13,43 & 13,30 & 21,94 \\
\hline & Standard deviations & 9,90 & 10,48 & 8,05 & 5,11 & 9,06 & 8,20 \\
\hline & RMSD & 0 & 6,94 & 5,24 & 8,73 & 10,33 & 7,34 \\
\hline & $\mathrm{r}$ & 1,00 & 0,77 & 0,85 & 0,47 & 0,41 & 0,69 \\
\hline \multirow{4}{*}{$\begin{array}{l}\text { Cold } \\
\text { season }\end{array}$} & Means & 17,09 & 20,46 & 18,90 & 13,30 & 14,38 & 19,62 \\
\hline & Standard deviations & 7,60 & 7,34 & 6,53 & 4,49 & 7,45 & 5,87 \\
\hline & RMSD & 0 & 5,59 & 3,84 & 6,17 & 8,15 & 5,78 \\
\hline & $\mathrm{r}$ & 1,00 & 0,72 & 0,86 & 0,58 & 0,41 & 0,66 \\
\hline
\end{tabular}

252

253

Three different statistics are analyzed: mean, standard deviation (STD), Root-Mean-Square Deviation (RMSD) and the correlation coefficient of Bravais-Pearson ( $r$ instead of $\mathrm{R}^{2}$ ). The lower the RMSD, the closer the variant is to the reference and is therefore able to reproduce the reference values (Taylor, 2001).

The results show that, with the density profiles, the point representing the variant D (HT Dens Thres) is closer to the reference (Visu Dens) than all the other points in the hot season and in the cold season. Statistics from Taylor diagrams indicate that only the two variants, B (HT Dens Algo) and D (HT Dens Thres) have high correlation coefficients. HT Dens Thres is nevertheless the highest compared to the other variants $(\mathrm{B}, \mathrm{J}, \mathrm{F}, \mathrm{H})$ and is 0.85 in hot season and 0.86 in cold season. Its standard deviation is 8.05 during the hot season and 6.53 during the cold season, and its distance from Visu Dens (RSMD) is 5.24 and 3.84, respectively, in hot and cold seasons. In addition, the average MLD determined with HT Dens Thres are the closest to the MLD averages visually determined on the density profiles.

The Taylor diagrams based on the Visu Temp reference show that three variants, C (HT Temp Thres), E (HT Temp Grad) and G (LORB Temp) are the closest to the reference with respect to two other variants A and I (Fig. 3). In addition, Table 7 shows the statistical parameters determined for these diagrams based on the temperature profiles. 
Table 7: Statistical parameters from Taylor diagram based on the reference Visu Temp. The MLD estimates from variants A, C, E, G and I are compared to those from visual determination on temperature profiles. RMSD: RootMean-Square Deviation. $\mathrm{r}$ and $\mathrm{R}^{2}$ : Bravais-Pearson correlation coefficient. For abbreviations refer to Table 2.

\begin{tabular}{|c|c|c|c|c|c|c|c|}
\hline & Statistical parameters & $\begin{array}{l}\text { Reference: } \\
\text { Visu Temp }\end{array}$ & $\begin{array}{l}\text { HT Temp } \\
\text { Algo } \\
\text { (A) }\end{array}$ & $\begin{array}{c}\text { HT } \\
\text { Temp } \\
\text { Thres } \\
\text { (C) }\end{array}$ & $\begin{array}{c}\text { HT } \\
\text { Temp } \\
\text { Grad } \\
\text { (E) }\end{array}$ & $\begin{array}{l}\text { LORB } \\
\text { Temp } \\
\text { (G) }\end{array}$ & $\begin{array}{l}\text { TF } \\
\text { Temp } \\
\text { (I) }\end{array}$ \\
\hline \multirow{4}{*}{$\begin{array}{c}\text { Hot } \\
\text { season }\end{array}$} & Means & 19,42 & 25,08 & 23,76 & 17,71 & 19,64 & 25,32 \\
\hline & Standard deviations & 10,00 & 9,36 & 9,03 & 8,14 & 9,86 & 9,51 \\
\hline & RMSD & 0 & 7,61 & 5,01 & 6,40 & 4,86 & 7,74 \\
\hline & $\mathrm{r}$ & 1,00 & 0,69 & 0,87 & 0,77 & 0,88 & 0,69 \\
\hline \multirow{4}{*}{$\begin{array}{c}\text { Cold } \\
\text { season }\end{array}$} & Means & 17,35 & 21,86 & 20,79 & 16,53 & 18,24 & 21,23 \\
\hline & Standard deviations & 8,19 & 8,12 & 7,23 & 6,53 & 8,07 & 8,05 \\
\hline & RMSD & 0 & 6,51 & 4,11 & 4,46 & 5,08 & 7,47 \\
\hline & $\mathrm{r}$ & 1,00 & 0,68 & 0,87 & 0,84 & 0,80 & 0,58 \\
\hline
\end{tabular}

The same variants HT Temp Thres, HT Temp Grad and LORB Temp have the strongest correlations with Visu Temp unlike TF Temp for both seasons. However, the RMSD values of variants HT Temp Thres and LORB Temp are the weakest. For variant LORB Temp in hot season $(\mathrm{RMSD}=4.86$, mean $=19.64$ against 19.42 for reference) and for HT Temp Thres in cold season $(\mathrm{RMSD}=4.11$, mean $=20.79$ against 17.35 for the reference $)$.

The different results seem to show that, whatever the season, the HT Dens Thres variant of the HT method is the most appropriate for determining the MLD from the density profiles. With the temperature profiles the results of the Taylor diagrams show at this stage that are the variants LORB Temp and HT Temp Thres that should be used to determine the MLD respectively in hot season and cold season. Since it is impossible to definitively conclude from the Taylor diagrams at least as regards the temperature profiles, it is necessary to observe the $2 \mathrm{D}$ diagrams to refine the choice of the appropriate method.

\subsection{Evaluation of methods using correlation diagrams}

The $p$-values and linear correlation coefficients between the numerical methods HT, LORB, TF and the visual methods are given in Table 8. 
Table 8: $p$-value and correlation coefficients between numerical and visual estimates for hot and cold season. Correlation coefficients substantially greater than 0.519 are in bold. For abbreviations refer to Table 2 .

\begin{tabular}{|c|c|c|c|c|c|}
\hline & \multirow{2}{*}{ Methods variants } & \multicolumn{2}{|c|}{ p-values } & \multicolumn{2}{|c|}{ Correlation coefficients $\left(\mathrm{R}^{2}\right)$} \\
\hline & & Visu Temp & Visu Dens & Visu Temp & Visu Dens \\
\hline \multirow{10}{*}{ Hot season } & HT Temp Algo & 5.63.E-38 & 3.86.E-33 & 0.48036 & 0.432977 \\
\hline & HT Dens Algo & 7.07.E-47 & 1.92.E-51 & 0.557546 & 0.592607 \\
\hline & HT Temp Thres & 1.38.E-78 & 1.69.E-68 & 0.750718 & 0.70077 \\
\hline & HT Dens Thres & 1.07.E-67 & 1.92.E-72 & 0.696407 & 0.721395 \\
\hline & HT Temp Grad & 2.32.E-51 & 8.29.E-50 & 0.591992 & 0.580385 \\
\hline & HT Dens Grad & 7.61.E-16 & 1.13.E-15 & 0.226072 & 0.223701 \\
\hline & LORB Temp & 2.48.E-84 & 1.47.E-83 & 0.775351 & 0.772184 \\
\hline & LORB Dens & 7.03.E-12 & 1.02.E-11 & 0.169291 & 0.166889 \\
\hline & TF Temp & 5.51.E-37 & 2.81.E-33 & 0.470994 & 0.434373 \\
\hline & TF Dens & 7.03.E-34 & 5.85.E-37 & 0.440484 & 0.470733 \\
\hline \multirow{10}{*}{ Cold season } & HT Temp Algo & 7.9.E-37 & 8.3.E-29 & 0.464238 & 0.382221 \\
\hline & HT Dens Algo & 2.48.E-39 & 5.94.E-43 & 0.487553 & 0.519509 \\
\hline & HT Temp Thres & 2.7.E-79 & 3.45.E-58 & 0.748485 & 0.633648 \\
\hline & HT Dens Thres & 1.58.E-68 & 1.19.E-78 & 0.695272 & 0.74558 \\
\hline & HT Temp Grad & 2.67.E-70 & 4.19.E-51 & 0.704743 & 0.584384 \\
\hline & HT Dens Grad & 2.02.E-27 & 4.E-25 & 0.366836 & 0.340542 \\
\hline & LORB Temp & 1.95.E-60 & 5.07.E-45 & 0.648025 & 0.536879 \\
\hline & LORB Dens & 2.84.E-13 & 3.57.E-12 & 0.187022 & 0.171173 \\
\hline & TF Temp & 1.79.E-24 & 5.22.E-19 & 0.332883 & 0.265174 \\
\hline & TF Dens & 8.14.E-33 & 6.92.E-34 & 0.424648 & 0.435481 \\
\hline
\end{tabular}

The 2D correlation diagrams between these variants and the Visu Temp and Visu Dens references in hot and cold seasons are shown in Fig. 4 and 5. All the p-value are $<0.05$, indicating that all correlations are highly significant at the 5\% level. The analysis of the values of the correlation coefficients shows that five variants have stronger correlations with Visu Temp and Visu Dens references in hot and cold seasons. These are HT Dens Algo and HT Dens Thres on density profiles, HT Temp Thres, HT Temp Grad and LORB Temp on temperature profiles. 


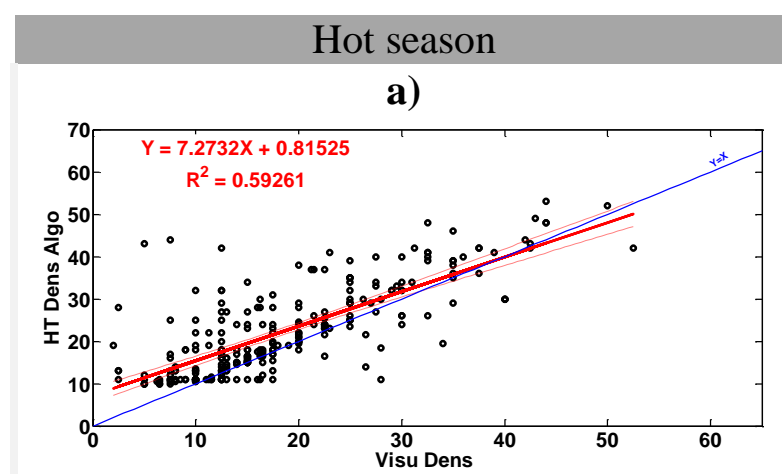

b)

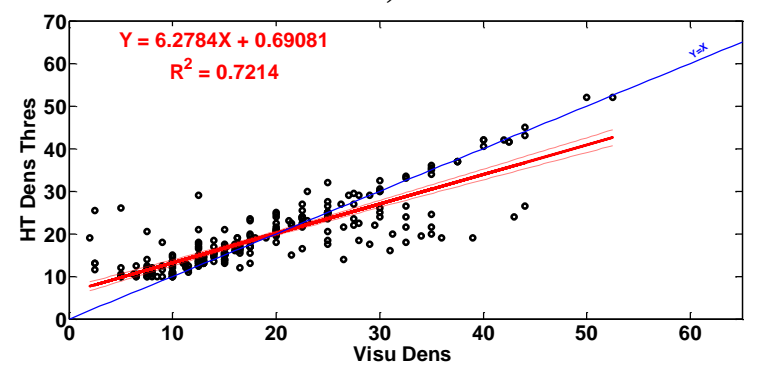

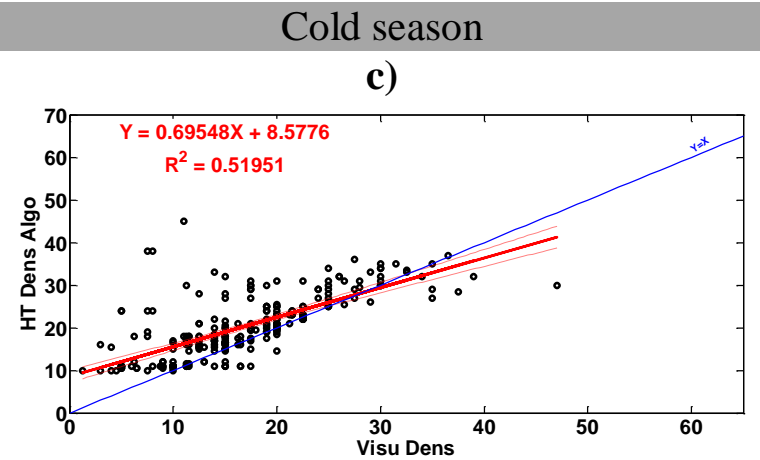

d)

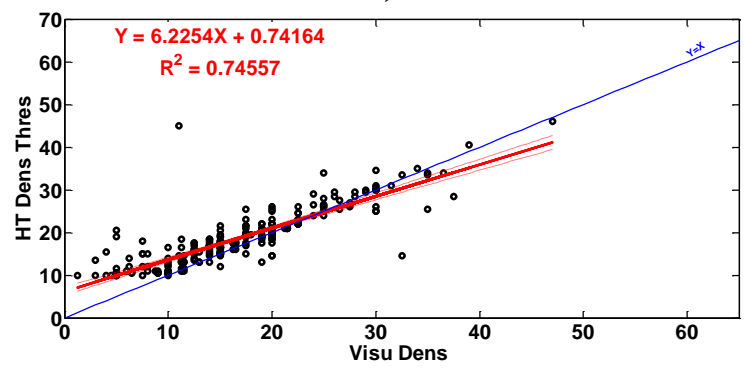

Fig. 4 2D correlation diagrams between Visu Dens and both variants B (HT Dens Algo) and D (HT Dens Thres) for MLD estimated from density profiles. Diagrams a, b for hot season and c, d for cold season.
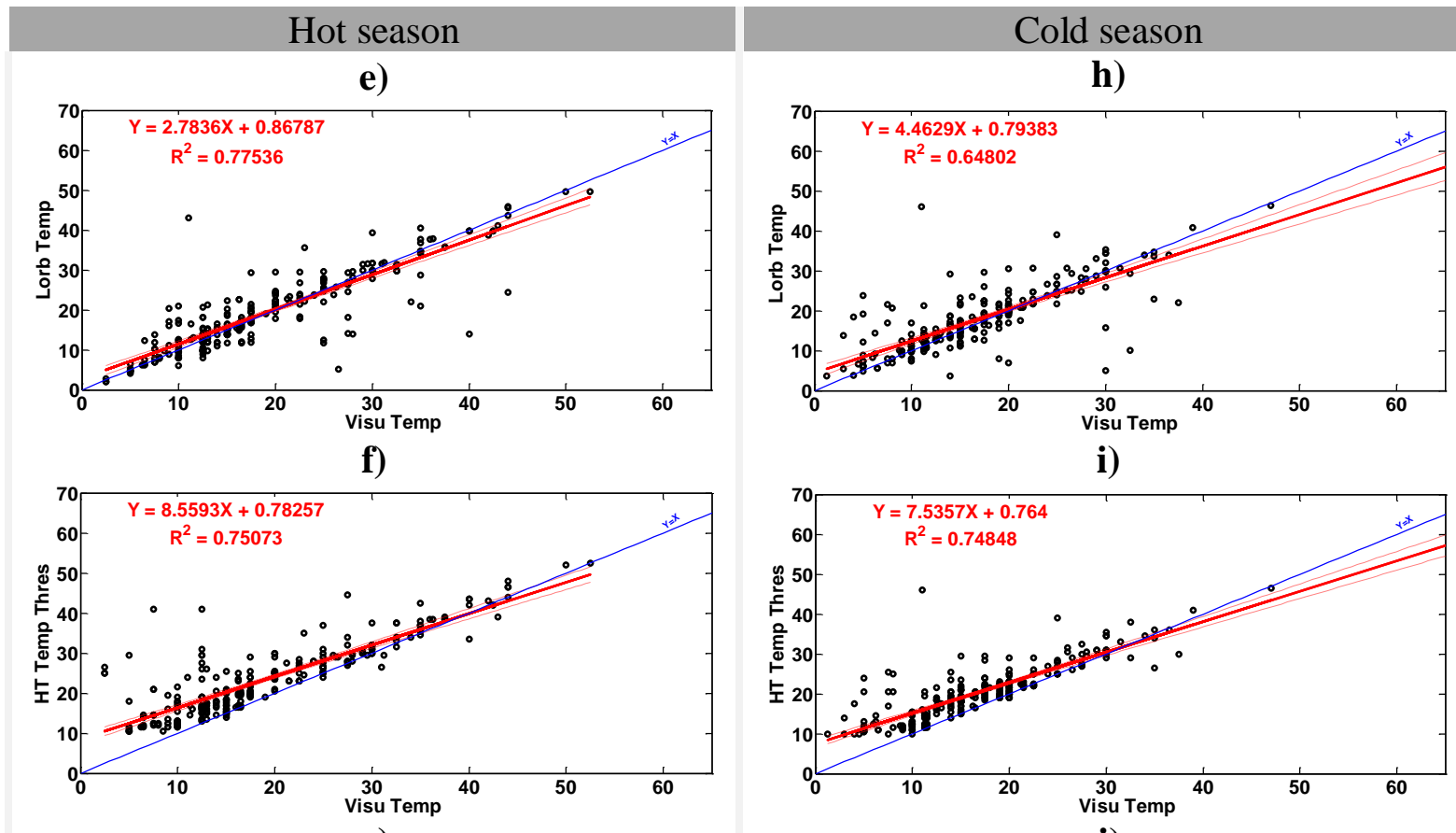

g)
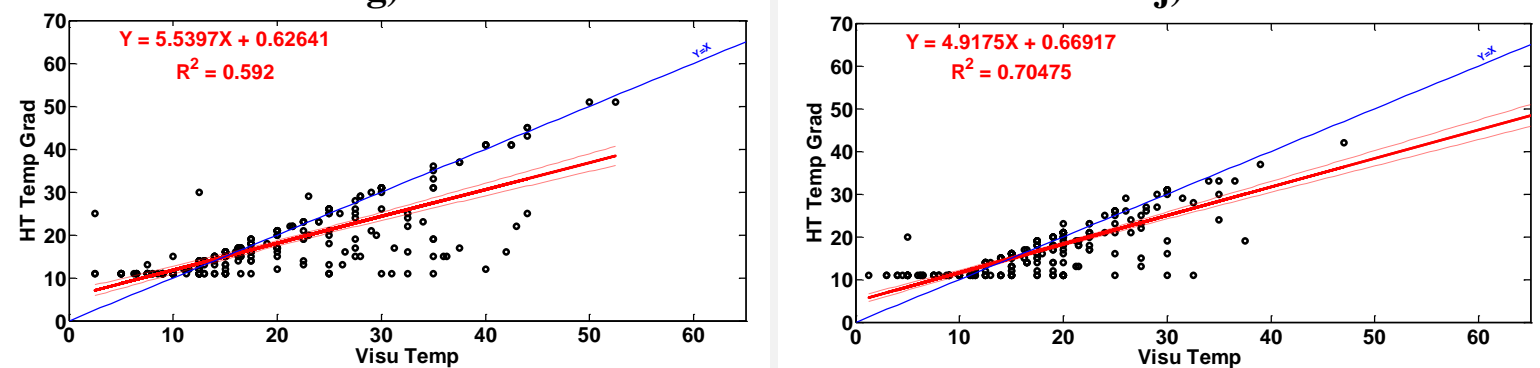

Fig. 5 2D correlation diagrams between Visu Temp and the three variants C (HT Temp Thres), E (HT Temp Grad) and G (LORB Temp) for MLD estimated from temperature profiles. Hot season (e, f, g). Cold season (h, $\mathrm{i}, \mathrm{j})$. 
With the temperature profiles, the 2D diagrams show that HT Temp Thres overestimates the MLD, HT Temp Grad underestimates them, while LORB Temp gives MLD comparable to the Visu Temp reference.

Our results show that the de Boyer Montegut density threshold method (potential density) with the constant criterion $\Delta \sigma=0.03 \mathrm{~kg} \cdot \mathrm{m}^{-3}$ and a reference depth of ten meters is the most appropriate for determining the MLD in the Gulf of Guinea regardless the season. These results thus point to the prevalence of the threshold criterion and the choice of density (which takes into account both temperature and salinity) in the determination of the MLD. Schneider and Müller (1990), Brainerd and Gregg (1995) as well as Thomson and Fine (2003) demonstrated that the MLD obtained from a threshold criterion is more stable than the MLD based on a gradient criterion and give values that are closer to the "real" MLD. Moreover, according to Lukas and Lindstrom (1991), a criterion based on potential density produces more reliable MLD than a temperature criterion because the temperature would not adequately account for vertical stratification in many regions. This is corroborated by Thomson and Fine (2003) who recommend using the potential density for the MLD because the density directly affects the stability and degree of turbulent mixing of the water column. In addition, the existence of barrier layers, as shown by our results, generally leads to the definition of the depth of the mixing layer more adequately by a density criterion (Peter, 2007).

In the situation where temperature profiles data are only available it is advisable to estimate MLD using the Lorbacher curvative method. The MLD determined with the temperature profiles overestimate those obtained with the density profiles whatever the chosen criterion (threshold, gradient, alternative algorithms). In particular, the method based on the temperature threshold $\Delta \mathrm{T}=0.2^{\circ} \mathrm{C}$ of de Boyer Montegut et al. (2004) overestimates the MLD compared to the method of Lorbacher et al. (2006) applied to temperatures. These results are in agreement with those of Lukas and Lindstrom (1991) and Sprintall and Tomczak (1992) who have shown that threshold methods, especially those based solely on temperature, intrinsically overestimate MLD. To support this result, Holte and Talley (2009), whose work has addressed the Sub-Antarctic Water Formation and Antarctic Intermediate Water regions, also found that threshold methods tend to overestimate the MLD compared to temperature and density algorithms. 
339 Five hundred and sixteen (516) MLD values including 260 for the cold season and 256 for the 340 hot season are determined using the HT, TF and LORB numerical methods. The maximum 341 MLD are obtained from the temperature profiles with the TF and HT methods and the lowest 342 MLD with LORB methods regardless the season. These numerical results, compared with the 343 visual measurements (representing the reference values obtained by visual inspection of all the 344516 profiles of temperature and density) through statistical and graphical analyses using the 345 Taylor and 2D correlation diagrams, show that the HT density threshold method (potential 346 density) with the constant criterion $\Delta \sigma=0.03 \mathrm{~kg} \cdot \mathrm{m}^{-3}$ and a reference depth of ten meters is the 347 most appropriate for determining the MLD in the Gulf of Guinea regardless the season. In the 348 situation where temperature profiles data are only available it is advisable to estimate MLD 349 using the Lorbacher curvative method.

351 Conflict of Interest statement: On behalf of all authors, the corresponding author states that 352 there is no conflict of interest. 
Alboukadel K (2018) ggcorrplot: Visualization of a Correlation Matrix using 'ggplot2'. R package version 0.1.2. https://CRAN.R-project.org/package=ggcorrplot

Binet D, Marchal E (1993) The Large Marine Ecosystem of Shelf Areas in the Gulf of Guinea: LongTerm Variability Induced by Climatic Changes. In: Large Marine Ecosystems - Stress Mitigation and Sustainability. K. Sherman, L.M. Alexander and B. Gold, Eds. American Association for the Advancement of Science, Washington. pp. 104-118.

Boyer TP, Antonov JI, Baranova OK, Coleman C, Garcia HE, Grodsky A, Johnson DR, Locarnini RA, Mishonov AV, O'Brien TD, Paver CR, Reagan JR, Seidov D, Smolyar IV, Zweng MM (2013) World Ocean Database 2013. Sydney Levitus, Ed.; Alexey Mishonov, Technical Ed.; NOAA Atlas NESDIS 72, 209 pp.

Brainerd KE, Gregg MC (1995) Surface mixed and mixing layer depths, Deep Sea Res., Part I, 42(9), $1521-1543$.

de Boyer Montégut C, Madec G, Fischer AS, Lazar A, Ludicone D (2004) Mixed layer depth over the global ocean: an examination of profile data and a profile-based climatology. Journal of Geophysical Research, 109:C12003. doi : 10.1029/2004JC002378.

Hardman-Mountford NJ (2000) Environmental variability in the Gulf of Guinea large marine ecosystem: physical features, forcing and fisheries. $\mathrm{PhD}$ thesis, University of Warwick.

Holte J, Talley L (2009) A New Algorithm for Finding Mixed Layer Depths with Applications to Argo Data and Subantarctic Mode Water Formation. J. Atmos. Oceanic Technol., 26, 19201939, https://doi.org/10.1175/2009JTECHO543.1

Kara AB, Rochford PA, Hurlburt HE (2000) An optimal definition for ocean mixed layer depth. Journal of Geophysical Research., 105(C7), 16,80316,821. https://doi.org/10.1029/2000JC900072

Kara AB, Rochford PA, Hurlburt HE (2003) Mixed layer depth variability over the global ocean. J Geophys Res. 108: 1-15. doi: 10.1029/2000JC000736

Lorbacher K, Dommenget D, Niiler PP, Köhl A (2006) Ocean mixed layer depth. A subsurface proxy of oceanatmosphere variability, J. Geophys. Res.-Oceans, 111, 1-22, https://doi.org/10.1029/2003JC002157, 2006.

Lukas R, Lindstrom E (1991) The mixed layer of the western equatorial Pacific Ocean, J. Geophys. Res., 96( S01), 3343-3357, doi:10.1029/90JC01951.

Maheswaran PA (2004) Mixed Layer Characteristics and Hydrography off the West and East Coasts of India. Cochin University of Science and Technology. Fac. Mar. Sci. Kerala, India. http://dyuthi.cusat.ac.in/purl/779

Mignot J, de Boyer Montégut C, Lazar A, Cravatte S (2007) Control of salinity on the mixed layer depth in the world ocean: 2. Tropical areas, J. Geophys. Res., 112, C10010, doi:10.1029/2006JC003954.

Nahavandian ES (2014) Temporal and spatial evolution of the mixed layer in the southern Beaufort Sea and the Amundsen Gulf. Thèse. Québec, Université du Québec, Institut national de la recherche scientifique, Doctorat en sciences de l'eau, $223 \mathrm{p}$

Nieto K, Mélin F (2017) Variability of chlorophyll-a concentration in the Gulf of Guinea and its relation to physical oceanographic variables. Prog. Oceanogr., 151, pp. 97-115. https://doi.org/10.1016/j.pocean.2016.11.009

Ohno Y, Iwasaka N, Kobashi F et al. (2009) Mixed layer depth climatology of the North Pacific based on Argo observations. J Oceanogr 65: 1. https://doi.org/10.1007/s10872-009-0001-4

Peter AC, Le Hénaff M, du Penhoat Y, Menkès C E, Marin F et al. (2006) A model study of the seasonal mixed layer heat budget in the equatorial Atlantic. Journal of Geophysical Research, American Geophysical Union. 111, pp.C06014. doi: 10.1029/2005JC003157 
Peter AC (2007) Variabilité de la temperature de la couche de mélange océanique en Atlantique equatorial aux échelles saisonnières à interannuelles, à l'aide de simulation numérique. Océan, Atmosphère. Université Paul Sabatier - Toulouse III. French. <tel-00157983>

Schneider N, Müller P (1990) The meridional and seasonal structure of the mixed-layer depth and its diurnal amplitude observed during the Hawaii-to-Tahiti Shuttle experiment. Journal of Physical Oceanography, 20(9):1395-1404

Sprintall J, Roemmich D (1999) Characterizing the structure of the surface layer in the pacic ocean. J. Geophys. Res., 104(C10):23297-23311. https://doi.org/10.1029/1999JC900179

Sprintall J, Tomczak M (1992) Evidence of the barrier layer in the surface layer of the tropics. J. Geophys. Res., 97, 7305-7316. https://doi.org/10.1029/92JC00407

Taï JH, Wong GTF, Pan X (2017) Upper water structure and mixed layer depth in tropical waters: The SEATS station in the northern South China Sea. Terr. Atmos. Ocean. Sci., 28, 1019-1032, doi: 10.3319/TAO.2017.01.09.01

Tanguy Y, Arnault S, Philippe L (2010) Isothermal, mixed, and barrier layers in the subtropical and tropical Atlantic Ocean during the ARAMIS experiment. Deep Sea Research Part I: Oceanographic Research Papers. 57. 501-517. 10.1016/j.dsr.2009.12.012.

Taylor KE (2001) Summarizing multiple aspects of model performance in a single diagram. J. Geophys. Res. 106: 7183-7192. doi:10.1029/2000JD900719.

Thomson RE, Fine IV (2003) Estimating Mixed Layer Depth from Oceanic Profile Data. J. Atmos. Oceanic Technol., 20, 319-329. https://doi.org/10.1175/15200426(2003)020<0319:EMLDFO>2.0.CO;2

Thomson RE, Fine IV (2009) A Diagnostic Model for Mixed Layer Depth Estimation with Application to Ocean Station $\mathrm{P}$ in the Northeast Pacific. J. Phys. Oceanogr.,39, 13991415, https://doi.org/10.1175/2008JPO3984.1

Tilot V, King A (1993) A review of the subsystems of the canary current and Gulf of Guinea large marine ecosystems. IUCN Marine Programme. In Hardman-Mountford NJ (2000) Environmental variability in the Gulf of Guinea large marine ecosystem: physical features, forcing and fisheries. $\mathrm{PhD}$ thesis, University of Warwick

Wade M (2010) Caractérisation de la couche limite océanique pendant les campagnes EGEE/AMMA dans l'Atlantique Équatorial Est. Océan, Atmosphère. Université Paul Sabatier - Toulouse III. 〈tel01020065>

You Y (1995) Salinity Variability and Its Role in the Barrier-Layer Formation during TOGACOARE. J. Phys. 0485(1995)025<2778:SVAIRI>2.0.CO;2 